NBER WORKING PAPER SERIES

\title{
INCOMPLETE CONTRACTS AND \\ INDUSTRIAL ORGANIZATION
}

\author{
Gene M. Grossman \\ Elhanan Helpman \\ Working Paper 7303 \\ http://www.nber.org/papers/w7303 \\ NATIONAL BUREAU OF ECONOMIC RESEARCH \\ 1050 Massachusetts Avenue \\ Cambridge, MA 02138 \\ August 1999
}

We thank Patrick Bolton, Eddie Deckel, Oliver Hart, Ariel Rubinstein, and Manuel Trajtenberg for helpful comments and the National Science Foundation through the NBER and the US-Israel Binational Science Foundation for financial support. The views expressed herein are those of the authors and not necessarily those of the National Bureau of Economic Research.

() 1999 by Gene M. Grossman and Elhanan Helpman. All rights reserved. Short sections of text, not to 
exceed two paragraphs, may be quoted without explicit permission provided that full credit, including $\odot$ notice, is given to the source.

Incomplete Contracts and Industrial Organization

Gene M. Grossman and Elhanan Helpman

NBER Working Paper No. 7303

August 1999

JEL No. D23, D43, D51

\section{$\underline{\text { ABSTRACT }}$}

We develop an equilibrium model of industrial structure in which the organization of firms is endogenous. Differentiated consumer products can be produced either by vertically integrated firms or by pairs of specialized companies. Production of each variety of consumer good requires a unique, specialized component. Vertically integrated firms can manufacture the components they need in the quantity and type that maximizes profits, but they face a relatively high cost of governance. Specialized firms can produce at lower cost, but input suppliers face a potential hold-up problem. We study the equilibrium mode of organization when inputs are fully or partially specialized. We consider how the degree of competition in the market and other parameters affect the equilibrium choices, and how the equilibrium compares with the efficient allocation.

Gene M. Grossman

Woodrow Wilson School

Princeton University

Princeton, NJ 08544-101

and NBER

grossman@princeton.edu
Elhanan Helpman

Department of Economics

Harvard University

Cambridge, MA 02138

and NBER

ehelpman@harvard.edu 


\section{Introduction}

The "make or buy" decision is fundamental to industrial organization. Hundreds of activities go into the sale of a finished product, from basic research to product design, from preparation and installation of machinery and the production of components, to assembly, packing, marketing and shipping. For each such activity, a producer must decide whether to undertake the activity in house or to purchase the input or service from outside. As Coase (1937) emphasized long ago, the cumulation of these decisions defines the boundaries of the firm.

Industrial organization evolves over time. First, putting-out gave way to the factory system. Then dramatic changes in the organization of factories occurred with the advent of steam power and, later, electricity. Interchangeable parts enabled mass production as well as horizontal and vertical specialization. Now, advances in communication technology and in computer-aided design are transforming again the way production is organized.

An interesting trend has been noted recently by several empirical researchers. In many industries, firms are outsourcing inputs and services that formerly they would have produced in house. Vertical disintegration is evident especially in international trade. The most recent annual report of the World Trade Organization (1998) details, for example, the production of a particular "American" car:

Thirty percent of the car's value goes to Korea for assembly, 17.5 percent to Japan for components and advanced technology, 7.5 percent to Germany for design, 4 percent to Taiwan and Singapore for minor parts, 2.5 percent to he United Kingdom for advertising and marketing services, and 1.5 percent to Ireland and Barbados for data processing. This means that only 37 percent of the production value ... is generated in the United States. (p.36)

Feenstra (1998), citing Tempest (1996), describes similarly the production of the Barbie doll. According to Feenstra, Mattel procures raw materials (plastic and hair) from Taiwan and Japan, conducts assembly in Indonesia and Malaysia, buys the molds in 
the United States, the cloth for dresses in China, and the paints used in decorating the dolls in the United States. Audet (1996), Campa and Goldberg (1997), Hummels et al. (1998) and Yeats (1998) have made more systematic efforts to assess the phenomenon. Using trade in intermediate inputs or in parts and components to measure what they variously termed 'vertical specialization', 'intra-product specialization' and 'global production sharing', these authors find rapid growth in international specialization for a varied group of industries including textiles, apparel, footwear, industrial machinery, electrical equipment, transportation equipment, and chemicals and allied products. $^{1}$

What accounts for the increasing degree of specialization in production? Which industries will be most affected and which stages of production? What are the consequences for economic efficiency and the implications for trade and competition policies? In order to address these questions and others like them, we need an equilibrium model of industrial structure in which the organization of firms is endogenous.

Contract theory has been instrumental in advancing our understanding of a firm's outsourcing decisions. Following the seminal work of Williamson $(1975,1985)$ and Grossman and Hart (1986), much research has been devoted to clarifying the roles of transaction costs, asset specificity, and incomplete contracts in guiding the choice between in-house production and outsourcing. This work has focused on the individual firm, however, or on the bilateral relationship between a single producer and its potential supplier. As such, it is not fully suitable for analysis of industry trends, because the attractiveness of options available to a firm may well depend on the decisions of others.

Our aim in this paper is to use building blocks from the work of Williamson and others to construct an equilibrium theory of industrial organization. ${ }^{2}$ Our model helps to clarify some of the interdependencies in the outsourcing choices of individual firms

\footnotetext{
${ }^{1}$ See also Abraham and Taylor (1996) for evidence of rising outsourcing of business services in thirteen industries and Helper (1991) on the increased outsourcing of parts in the U.S. automobile sector.

${ }^{2}$ See McLaren (1998) for an interesting predecessor which, however, was constructed to make a more narrow point.
} 
and enables us to derive conditions under which an industry will be organized in a particular way. We believe it will prove useful for studying the trends in international specialization, including the increased prevalence of multinational corporations, the growing tendency to outsource in foreign countries, and the expanding number and types of contractual relationships with foreign suppliers. These issues of "globalization" are the focus of ongoing research.

In the first part of this paper we develop a simple model that can be used to examine equilibrium modes of industrial organization. In the model, differentiated consumer products can be produced either by vertically integrated firms or by pairs of specialized companies. In the latter case, one firm manufactures an intermediate input while another designs and assembles a variety of the final product. The production of each variety of consumer good requires a unique, specialized component. Vertically integrated firms can manufacture the components they need in the quantity that maximizes profits. However, such firms face relatively high fixed and variable production costs, due to their lack of complete specialization and to the extra governance costs associated with their extensive organizations. Specialized firms may be able to produce at lower cost, but they suffer from a different problem. As in the literature on incomplete contracts (see, for example, Hart, 1995) we assume that the quality and other particulars of a specialized component are not verifiable by an outside party. This means that no contract can stipulate the exchange of a given quantity at a specified price. If such a contract existed, the input supplier would be tempted to save costs by shaving quality. In its absence, however, the input supplier faces a potential hold-up problem. The final producer can negotiate (or renegotiate) the price after the component has been produced, at which time the input will have limited value in alternative uses. For this reason, a specialized producer has a diminished incentive to produce a large volume of components. The trade-off between the potential excess governance costs of vertical integration and the potential inefficiency associated with ex post bargaining determines the equilibrium mode of organization in our model.

After outlining the model in the next section, we characterize in Section 3 an 
equilibrium with pervasive outsourcing. Such an equilibrium exists if the cost disadvantage for vertically integrated firms is sufficiently large. More interesting are our findings concerning the degree of competition, which we discuss in some detail. Outsourcing cannot arise if producers of consumer goods have sufficient monopoly power. But it also cannot occur when competition is very intense and the (variable) cost advantage of specialized input producers is modest. For moderate differences in the cost of producing components, outsourcing requires an intermediate degree of substitutability between final products.

Section 4 examines equilibria with vertical integration. An equilibrium in which all firms are integrated always exists and has properties that are familiar from standard models of monopolistic competition. However, when conditions are such that either mode of organization can emerge as an equilibrium, the outcome with vertical integration may be considered fragile. In these circumstances, entry by a very small number of specialized intermediate and final producers will make the entry of large numbers of others profitable. We also show that equilibria with a mix of integrated and specialized firms do not exist (generically) in our model.

In Section 5, we examine the welfare properties of the alternative equilibria. We show that when an equilibrium with pervasive outsourcing exists, it yields greater welfare to consumers than an equilibrium with vertical integration. On the other hand, if an equilibrium with outsourcing does not exist, no inducement to entry by specialized firms could improve upon the equilibrium outcome with pervasive integration.

In the last part of the paper, we extend the model to allow for a secondary market in intermediate inputs. One might argue that the simple model overstates the hold-up problem, because input producers have no sale possibilities other than to the firm for whom the components have been designed. In reality, specialization typically occurs in stages, and it is often possible to recoup some of the investment if it becomes necessary to find a new partner. To capture this, we introduce components that differ in their degree of specialization. We associate with each final good an ideal component, which is the one most suitable for producing that good. But final producers can use inputs of different specifications at an additional cost. Now the 
bargaining between supplier and final producer takes place against a backdrop in which each side has an outside option.

We show in Section 6 that, if outsourcing occurs, the input producers specialize their components only partially. A more specialized input offers greater surplus inside the relationship with the intended customer. But a more generic input enhances the input producer's outside options and so improves its bargaining power. In equilibrium, the producer balances these two considerations and manufactures a component with an equilibrium degree of specialization. We discuss the details of this trade-off and derive conditions for the existence of an equilibrium with outsourcing in the extended model. An equilibrium with outsourcing is most likely to exist when the excess costs of a vertically integrated firm are great and the degree of competition in the market for final goods is neither too large nor too small. A new consideration is the sensitivity of final producer costs to the specifications of the component. Larger penalties for using less-than-ideal components need not favor vertical integration as the unique equilibrium outcome.

\section{A Simple Model}

We begin with a simple version of our model to develop intuition. In the simplified model, intermediate inputs must be fully tailored to a particular consumer product or else they are worthless to the final producer. With this assumption, input producers have no choice but to sell their output to the firm for whom it was designed. Later, we will allow final producers to use components that are not built precisely to their specifications. Then we will treat the degree of specialization as a choice variable of the input producers.

The economy produces many products. Goods are differentiated in the eyes of both producers and consumers. On the supply side, each good requires a special intermediate input. On the demand side, the goods are imperfect substitutes. We treat the product space as a continuum. 
Each consumer maximizes a utility function of the form

$$
u=\int_{0}^{n} y(i)^{\alpha} d i, \quad 0<\alpha<1
$$

where $y(i)$ is consumption of product $i$ and $n$ is the measure of products available on the market. As is well known, these preferences yield the demand functions

$$
y(i)=A p(i)^{-\frac{1}{1-\alpha}}
$$

where $p(i)$ is the price of product $i, A \equiv E / \int_{0}^{n} p(j)^{-\frac{\alpha}{1-\alpha}} d j$, and $E$ denotes spending. The unique supplier of variety $i$ treats $A$ as constant, and so perceives a constant elasticity of demand. Total spending equals aggregate income in the general equilibrium.

The technology for producing a variety is as follows. Each unit of output requires one unit of a specialized intermediate input. For now, the intermediate good must be exact in its specifications and each final good requires a distinct component. An input must also be of suitably high quality or else it is useless for producing output. Besides the intermediate good, there are no other variable inputs into final production. However, there are fixed costs associated with entering the market, searching for a partner, producing inputs, and assembling them into finished products, which we describe just below.

Final output may be produced by vertically integrated firms or by stand-alone enterprises that purchase their inputs at arms length. A firm that specializes in manufacturing intermediates can produce a high quality input with one unit of labor per unit of output. Alternatively, it can produce a low quality (and therefore useless) input at substantially lower cost. A vertically integrated firm requires $\lambda \geq 1$ units of labor to produce a unit of the (high quality) intermediate. The possibility that production costs may be higher for an integrated firm than for a stand-alone intermediate producer reflects the fact that its activities are not so highly specialized and that the bureaucratic cost of managing a larger operation may be higher. ${ }^{3}$

\footnotetext{
${ }^{3}$ Williamson (1985) emphasized that production by a vertically integrated firm may entail greater governance costs due to attenuated incentives and bureaucratic distortions. Some of these costs may be independent of scale, while others depend on the volume of output. We allow for both types of extra costs here.
} 
As for the fixed costs, these may vary by type of firm and mode of organization. The total fixed cost for a vertically integrated firm is $k$ units of labor. This includes the cost of entering the market (e.g., researching the market opportunities and setting up an organization), the cost of designing a product, the cost of installing capacity to produce intermediates, and the fixed governance costs for the organization as a whole. The fixed cost for a stand-alone producer of intermediates is $k_{I}$. We distinguish two components of this fixed cost, the "entry cost" $e_{I}$ and the "manufacturing cost" $m_{I}$; $e_{I}+m_{I}=k_{I}$. The entry cost here includes the cost of setting up the operation and of searching for a partner with whom to interact. The manufacturing cost includes the cost of designing the specialized input, of installing capacity to produce the input, and of managing the manufacturing process. These costs, unlike the entry costs, can be avoided by a firm that does not find a partner among final-good producers or that chooses not to produce a positive amount of the input. Finally, a stand-alone producer of final goods has fixed costs of $k_{F}$ (in labor units), with $k_{F}+k_{I} \leq k$. Here again, there are two components. The component $e_{F}$ comprises those costs that are sunk upon entry. This would include set-up costs, design costs, and the cost of searching for an input supplier. The remaining portion, $m_{F}$, encompasses the fixed cost of assembling the intermediate inputs into finished products and perhaps some governance and advertising costs. These can be avoided by a company that fails to find an intermediate supplier, but must be borne before the firm proceeds to the assembly stage.

Our setting is one of incomplete contracting. We suppose that the quality of an intermediate input can be observed by the participating firms, but cannot be verified by a court of law. The lack of verifiability precludes contracts between suppliers of inputs and potential buyers that stipulate a specified price for a pre-agreed quantity. If such a contract existed, an intermediate producer could reduce costs by shaving quality. The buyer would be obliged to buy the inferior products and would have no means to seek redress. Much has been written about possible alternatives to qualitycontingent contracts in contexts such as ours. For example, Aghion et al. (1994) argue that specific performance contracts coupled with certain renegotiation schemes 
sometimes can be used to promote efficient relationship-specific investments. Maskin and Tirole (1999) suggest alternative contract contingencies; in our economy, for example, a final-good producer might agree to compensate its input supplier based on the revenues received from sales of the final product. Since the final producer has no moral hazard in choosing its assembly or marketing efforts, the intermediate producer can be given the appropriate incentive to invest in quality. In response, Hart (1995), Segal (1999) and Hart and Moore (1999) have argued that there are settings in which these various fixes for incomplete contracts fail. We have nothing to add to the debate over the foundations of incomplete contracts, so we simply assume that they are a fact of life.

The absence of ex ante contracts creates a potential hold-up problem in our model. This problem is familiar from the writings of Williamson (1985), Klein et al. (1978), Hart (1995) and others. Once a producer of components specializes the inputs for a particular final good, the inputs have no value to other firms. The final-good producer can threaten to refuse delivery unless the price is sufficiently low. But an ex post negotiation of the price leaves the intermediate producer in a weak bargaining position, because the manufacturing costs are bygones by that time. Foreseeing this, the intermediate producer has insufficient incentive to produce the efficient quantity. The inefficiency that results from the hold-up problem gives a reason for vertical integration, which must be weighed against any excess governance costs that such an organizational structure entails.

Having described the technology for production and the limitations on contracting, let us detail the sequence of events in the economy. First, firms enter as either intermediate producers, final-good producers, or vertically-integrated entities. In each case, an entrant pays the relevant entry cost. Next, the stand-alone firms search for partners. A firm that has entered as an intermediate producer seeks a final-goods firm to serve with inputs. A producer of finished goods in turn seeks a supplier of specialized components. Matches occur randomly. If there are equal numbers of the two types of firms, every firm finds a partner. Otherwise, firms on the "long end" of the market have an equal probability of achieving a match, while firms on the "short 
end" are matched with probability one. ${ }^{4}$

When a pair of firms is matched, the final-good producer describes the input it needs. A firm that fails to find a match has no choice but to exit the market at this stage. After the specifications are conveyed, all integrated firms and matched intermediate-good producers manufacture their specialized inputs. These may be of high quality or low quality, and they may be produced in any quantity. At the same time, the final producers and integrated firms incur $m_{F}$, the fixed costs associated with assembly operations. Next, the stand-alone intermediate firms bring the inputs to their potential customers, and the partners negotiate the terms of trade. We assume that bargaining results equal sharing of surplus. Finally, all final-good producers and vertically integrated firms produce the differentiated products (at zero additional costs) and sell their wares to consumers.

To summarize, firms play a game with the following five stages: (1) entry, at which stage the fixed entry costs $e$ are incurred; (2) matching, at which stage unmatched firms exit; (3) production of intermediate inputs, at which stage the fixed manufacturing costs $m$ are incurred; (4) bargaining; and (5) production and sale of final goods.

We seek a general equilibrium in which the labor and product markets clear. Free entry ensures zero expected profits for each type of firm that enters in equilibrium. ${ }^{5}$ If some type of firm does not enter, then the expected profits for that type of firm must be negative or zero. The supply of labor is taken as fixed and equal to $L$. We choose labor as numeraire, so that the wage rate is always equal to one.

\footnotetext{
${ }^{4}$ In principle, a firm might enter as vertically integrated and nonetheless seek a potential partner. Then, if it fails to achieve a match, it can produce its own inputs. Even if it finds a partner, it might produce some inputs itself, in order to strengthen its bargaining position. However, these strategies will not be profitable if the search costs and the manufacturing costs are sufficiently high. We assume a cost structure such that vertically integrated firms will not wish to search for suppliers, without dwelling on the implied parameter restrictions.

${ }^{5}$ Uncertainty arises from the matching process. Since households can hold diversified portfolios of equities, firms maximize expected profits.
} 


\section{Pervasive Outsourcing}

In this section, we describe an equilibrium in which outsourcing is pervasive. In the equilibrium, all intermediate inputs are produced by firms that specialize in this activity. After describing the equilibrium, we derive the conditions under which it exists.

Let $n_{I}$ denote the number of firms that enter as intermediate-good producers and search for potential partners. Similarly, let $n_{F}$ denote the number of final-good entrants. If $n_{I} \geq n_{F}$, all final producers find a match with an intermediate producer, and the remaining $n_{I}-n_{F}$ intermediate producers forfeit their sunk investments and exit the industry. On the other hand, if $n_{F} \geq n_{I}$, all intermediate producers successfully match with final producers, and it is the excess of $n_{F}-n_{I}$ final producers that leave empty handed. In either case, the number of matches is dictated by the short end of the market. We will see that all matches yield positive output in equilibrium, so that

$$
n=\min \left\{n_{I}, n_{F}\right\} .
$$

Consider what happens after a match takes place. Suppose a certain intermediate producer meets up with the firm that has designed differentiated product $i$. The latter then hands over the specifications for its component. If the input producer were to manufacture $x(i)$ units of the component, the final producer would have the ability to produce $y(i)=x(i)$ units of variety $i$. The potential revenue from sales of these final goods is $A^{1-\alpha} x(i)^{\alpha}$, in light of the demand function given in (1).

Once the $x(i)$ units of the intermediates have been manufactured, the two firms will meet to negotiate an exchange. At this point, all costs are sunk. If the exchange takes place, the final producer stands to reap revenues of $A^{1-\alpha} x(i)^{\alpha}$. If, instead, the firms go their separate ways, revenues for each are zero. This is because the final producer has no other source for components at this stage, whereas the intermediate producer has a quantity of specialized inputs that are of no value to any other producer. It follows that the exchange generates a joint surplus of $A^{1-\alpha} x(i)^{\alpha}$. In the bargain, the firms divide the surplus evenly. 
Now roll back to the time when the intermediate firm must decide how much to produce and of what quality. The firm foresees a potential reward of $\frac{1}{2} A^{1-\alpha} x^{\alpha}$ from producing $x$ units of a high quality component. This it could do at a variable cost of $x$. If instead it produces low quality components, no transaction will occur and any manufacturing costs will be lost. The intermediate firm maximizes profits by choosing to produce high quality and by setting $x(i)=(2 / \alpha)^{-1 /(1-\alpha)} A$. With $y(i)=x(i)$, this generates a price for the final good of $p(i)=2 / \alpha$. All prices are the same in a symmetric equilibrium, so we drop the functional notation and write

$$
p=\frac{2}{\alpha} .
$$

Notice that the price is exactly twice what a unitary actor with a unit cost of one would charge. The diminished output and higher price reflect the distortionary impact of the imperfect contract.

The break-even conditions depend on the market structure. If $n_{I} \geq n_{F}$, all final producers find suppliers. Each such producer receives $p y=p x=A p^{-\alpha /(1-\alpha)}$ from consumers and pays half of this amount to its partner. In a symmetric equilibrium, $A=E / n p^{-\alpha /(1-\alpha)}$. Then operating profits for a final producer are $E / 2 n$. The firm breaks even if these profits cover the fixed costs of $k_{F}$. Finally, since spending equals aggregate income in the general equilibrium, and aggregate profits are zero, $E=L$ with labor as numeraire. Thus,

$$
n=\frac{L}{2 k_{F}}
$$

in the case we are describing. ${ }^{6}$

\footnotetext{
${ }^{6}$ It is also possible to calculate the number of firms that enter as prospective intermediate producers, using the condition that expected profits are zero for these firms. With $n=n_{F} \leq n_{I}$, the entrants find a match with probability $n / n_{I}$. If successful, they receive proceeds of $\frac{E}{2 n}$ and pay fixed and variable costs of $x+k_{I}=\frac{\alpha E}{2 n}+e_{I}+m_{I}$. If they fail to find a match, revenues are zero and entry costs of $e_{I}$ are lost. Therefore, expected profits are zero when

$$
\frac{n}{n_{I}}\left[\frac{(1-\alpha) L}{2 n}-e_{I}-m_{I}\right]+\frac{n_{I}-n}{n_{I}}\left(-e_{I}\right)=0
$$

or, with (4a),

$$
n_{I}=\frac{L}{2 e_{I}}\left(1-\alpha-\frac{m_{I}}{k_{F}}\right) .
$$
}


On the other hand, if $n_{F} \geq n_{I}$, every intermediate-good entrant finds a partner. In this case, the input producers break even, which means that their revenues just cover their fixed and variable costs. Proceeds from sales of intermediates are one half of revenues from final sales, or $E / 2 n$. Fixed costs are $k_{I}$, while variable costs are $x=E / n p=\alpha E / 2 n$. The first equality reflects the fact that $y=x$ and that total spending is spread evenly over the $n$ different varieties. The second equality uses (3). Zero profits for the intermediate producers requires $E / 2 n=k_{I}+\alpha E / 2 n$, or with $E=L{ }^{7}$

$$
n=\frac{(1-\alpha) L}{2 k_{I}} .
$$

Since (4a) applies when $n=n_{F} \leq n_{I}$, and (4b) applies when $n=n_{I} \leq n_{F}$, it follows that the number of final-good entrants exceeds the number of intermediategood entrants if and only if $k_{F}<k_{I} /(1-\alpha)$. Defining $\kappa=\max \left\{k_{F}, k_{I} /(1-\alpha)\right\}$, we can write the equilibrium measure of differentiated products succinctly as

$$
n=\frac{L}{2 \kappa} \text {. }
$$

Also, $x=y=L / n p$, which with (3) and (4) implies

$$
y=\alpha \kappa
$$

When it exists, equations (3), (4) and (5) characterize a general equilibrium with pervasive outsourcing.

For the existence of such an equilibrium, we require that it not be profitable for a vertically integrated firm to enter. If a vertically integrated firm were to enter, it

\footnotetext{
${ }^{7}$ Again, we can use the requirement of zero expected profits to compute the number of potential final-good producers that enter. With probability $\frac{n}{n_{F}}$ an entrant succeeds in finding a match, in which case profits are $\frac{E}{2 n}-k_{F}$. With probability $\frac{n-n_{F}}{n_{F}}$ its search ends in failure and losses total $e_{F}$. Zero expected profits implies

$$
\frac{n}{n_{F}}\left[\frac{L}{2 n}-e_{F}-m_{F}\right]+\frac{n_{F}-n}{n_{F}}\left(-e_{F}\right)=0
$$

or, with (4b),$$
n_{F}=\frac{L}{2 e_{F}}\left[1-\frac{(1-\alpha) m_{F}}{k_{I}}\right]
$$ 
would face a demand given by $(1)$, with $A=(E / n) p^{\alpha /(1-\alpha)}=2 \kappa(2 / \alpha)^{\alpha /(1-\alpha)}$. It would maximize profits by setting its price at a fixed multiple of marginal cost. Marginal cost for an integrated firm is $\lambda$, the cost of producing a specialized intermediate in house. The optimal price then is $\lambda / \alpha$. With this price the entrant makes sales of $\alpha \kappa(2 / \lambda)^{1 /(1-\alpha)}$, and its operating profits are $(1-\alpha) \lambda \kappa(2 / \lambda)^{1 /(1-\alpha)}$. Entry by the integrated firm is unprofitable if and only if these profits fall short of the entrant's fixed cost, $k$. We have proven ${ }^{8}$

Proposition 1 There exists an equilibrium with pervasive outsourcing if and only if

$$
\frac{k}{\kappa} \geq(1-\alpha) \lambda\left(\frac{2}{\lambda}\right)^{\frac{1}{1-\alpha}}
$$

where $\kappa=\max \left\{k_{F}, \frac{k_{I}}{1-\alpha}\right\}$.

When $k=k_{I}+k_{F}$ and $\lambda=1$, specialized production by stand-alone firms offers no cost advantage relative to integrated production. All that remains is the distortion that results from the hold-up problem, which favors vertical integration. It is easy to see that, in this case, (6) can never be satisfied. ${ }^{9}$ Not surprisingly, an equilibrium with pervasive outsourcing is more likely to exist the greater is the relative benefit of producing intermediates in a specialized firm (large $\lambda$ ) and the greater are the fixed costs of an integrated entity relative to those of the two stand-alone producers (large $k$, small $k_{I}$ and $k_{F}$ ).

The interesting part of Proposition 1 concerns the role of the parameter $\alpha$. This parameter measures the degree of competition in the consumer-goods market. If $\alpha$ is close to one, the finished goods are nearly perfect substitutes and the market is highly competitive. If $\alpha$ is close to zero, consumers view the goods as quite distinct and each firm enjoys considerable monopoly power. We turn now to an in-depth discussion of how the degree of competition in the product market affects the existence of an equilibrium with pervasive outsourcing.

\footnotetext{
${ }^{8}$ Formally, we must also check that a firm would not wish to enter as an integrated firm, search for an entrant, produce a quantity of its own intermediates, and then purchase additional intermediates from its partner. With $k \geq k_{I}+k_{F}$, it is possible to show that this is never profitable.

${ }^{9}$ With $k=k_{I}+k_{F}$, the left-hand side of (6) cannot exceed $2-\alpha$. With $\lambda=1$, the right-hand side equals $(1-\alpha) 2^{1 /(1-\alpha)}$, which is greater than $2-\alpha$ for all $\alpha \in(0,1)$.
} 


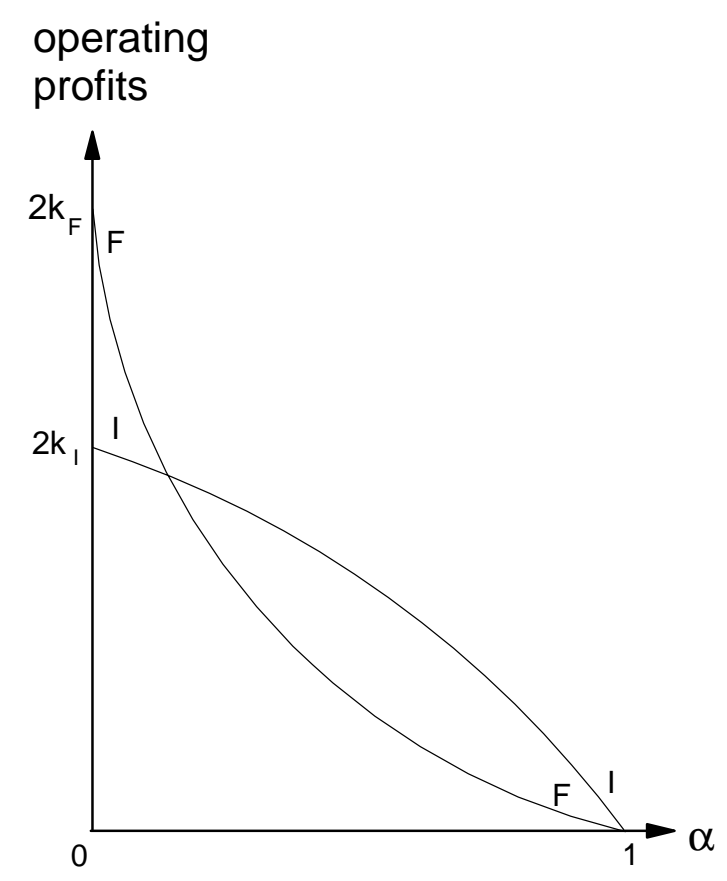

Figure 1: Existence of an equilibrium with pervasive outsourcing: $\lambda>2$

Suppose first that $\lambda>2$. In this situation, a specialized input producer enjoys a large cost advantage relative to a vertically integrated firm. Figure 1 shows two curves, labelled $F F$ and $I I$. The curve $F F$ plots the function $(1-\alpha) \lambda k_{F}(2 / \lambda)^{1 /(1-\alpha)}$; these are the operating profits of a vertically integrated entrant if $k_{F} \geq k_{I} /(1-\alpha)$ and thus $n_{I} \geq n_{F}$. With $\lambda>2$, this curve slopes downward. This is because the optimal price for the integrated producer is higher than the price charged by the specialized producers and a firm's revenues decrease with $\alpha$ when its own price exceeds the industry norm. Moreover, profits are a fraction $(1-\alpha)$ of revenues, so profit per dollar of sales falls with $\alpha$ as well. The curve $I I$ plots the function $\lambda k_{I}(2 / \lambda)^{1 /(1-\alpha)}$, which in turn is the operating profit of the entrant when $k_{I} /(1-\alpha) \geq k_{F}$. This curve too slopes downward when the cost disadvantage of the integrated producer is great. Again $\lambda>2$ implies a higher price for the integrated firm, which tends to make revenues fall with $\alpha$. But now the number of competitors falls with $\alpha$, which has an offsetting effect. But the effect $\alpha$ has on $n$ just offsets the impact it has on 


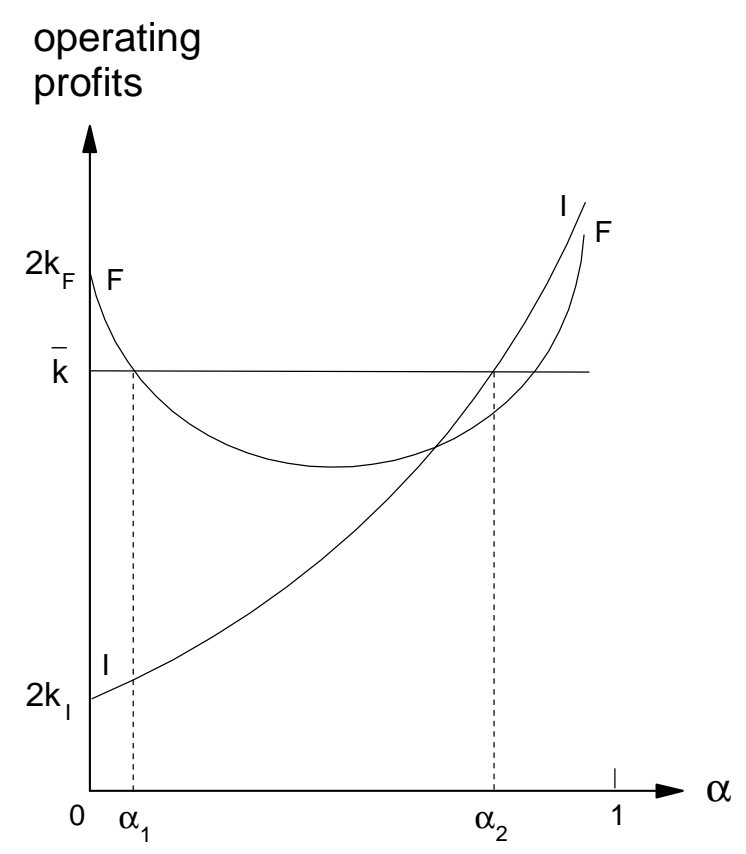

Figure 2: Existence of an equilibrium with pervasive outsourcing: $1<\lambda<2$

the profit margin, so the overall effect of an increase in $\alpha$ on the profitability of the integrated entrant is negative.

According to Proposition 1, an equilibrium with pervasive outsourcing exists if the fixed cost for a vertically integrated firm, $k$, exceeds the larger of these two profit levels. It is clear from the figure that this condition will be satisfied for all values of $\alpha$ when $k \geq 2 k_{F}$ and $k \geq 2 k_{I}$. Otherwise, there will be a range of (small) values of $\alpha$ for which entry by a vertically integrated firm would be profitable. In these cases, an equilibrium with pervasive outsourcing exists only if the differentiated products are sufficiently substitutable and thus a firm's monopoly power is not too great.

Now suppose that the cost advantage of specialized input producers is more modest; i.e., $1 \leq \lambda<2$. The relevant $F F$ and $I I$ curves for this case are depicted in Figure 2. Now, the operating profits of a vertically integrated firm increase with $\alpha$, provided $k_{I} /(1-\alpha) \geq k_{F}$. This is because the price set by the integrated firm now is lower than that of the stand-alone producers, so revenues rise with an increase in substitutability. On the other hand, if $k_{F} \geq k_{I} /(1-\alpha)$, the relationship between 
the integrated firm's operating profits and the degree of competition is U-shaped. Here, there are offsetting effects, in as much as an increase in $\alpha$ raises revenue for the integrated producer but reduces its profits per dollar of sales.

As before, the existence of an equilibrium with pervasive outsourcing requires that $k$ be greater than the larger of the two profit figures. In this case, pervasive outsourcing arises for intermediate degrees of product substitutability. The figure illustrates the comparison for a particular value of the fixed cost, $\bar{k}$. With this cost, pervasive outsourcing requires $\alpha \in\left[\alpha_{1}, \alpha_{2}\right]$. When $\alpha<\alpha_{1}$, the candidate equilibrium has $n_{I}>n_{F}$, but profitable entry by integrated firms destroys this potential equilibrium. When $\alpha>\alpha_{2}$, the candidate equilibrium has $n_{F}>n_{I}$, but again this leaves profit opportunities for integrated entrants.

To summarize, a market with highly differentiated products is not likely to be one with pervasive outsourcing, unless the excess (fixed) governance costs for the integrated firm are large. When final goods are highly differentiated, the profits of a firm do not vary much with its relative cost. In this situation, a vertically integrated entrant can pass along any cost disadvantage to consumers. At the same time, it does not benefit much from the price distortion generated by the imperfect contract between the specialized producers. If the fixed cost of governance are reasonable for the integrated firm, it can enter profitably and upset the equilibrium with pervasive outsourcing.

A market in which the final goods are close substitutes also is not likely to be one with pervasive outsourcing, if $\lambda<2$. Close substitutability makes profits highly sensitive to relative prices, and so entry by a vertically integrated firm will be profitable if and only if its optimal price is lower. The incomplete contract blunts the input producer's incentive to produce components, which tends to make the price of goods sold by specialized producers high. On the other hand, the relative cost advantage of these specialized firms tends to make their price low. If $\lambda<2$, the first effect dominates, and so integrated firms can enter a competitive market profitably, provided their excess governance costs are not too high. ${ }^{10}$

\footnotetext{
${ }^{10}$ Our formulation of arms-length dealing contains a mix of two frictions: matching and incomplete
} 


\section{Vertical Integration}

We turn next to equilibria with vertical integration (or self-production). First we describe an equilibrium in which all firms are vertically integrated. We show that such an equilibrium always exists, but that it may be fragile for some parameter values. Then we consider the possibility that vertically integrated firms and specialized firms co-exist in the market. Such an outcome cannot arise in our model, except as a knife-edge case.

\subsection{Pervasive Integration}

When all firms are vertically integrated, we have a standard setting of monopolistic competition. The conditions for an equilibrium are familiar from the work of Dixit and Stiglitz (1977) and others.

Each integrated firm faces a marginal production cost of $\lambda$ and a demand curve given by (1). The constant demand elasticity dictates mark-up pricing, so that

$$
\tilde{p}=\frac{\lambda}{\alpha}
$$

in a symmetric equilibrium. ${ }^{11}$ This pricing strategy yields operating profits per firm of $(1-\alpha) \tilde{E} / \tilde{n}$. With free entry, total profits are zero, and spending equals aggregate wage income of $L$. Thus, the break-even condition implies $(1-\alpha) L / \tilde{n}=k$, or

$$
\tilde{n}=\frac{(1-\alpha) L}{k}
$$

Finally, sales per brand amount to $\tilde{E} / \tilde{n} \tilde{p}$, or using (7) and (8),

$$
\tilde{y}=\frac{\alpha k}{(1-\alpha) \lambda}
$$

contracting. Both are realistic problems for specialized producers. In order to isolate the matching problem, however, the appendix examines an economy in which stand-alone firms can write complete contracts. We show there that an equilibrium with pervasive outsourcing exists whenever the entry costs of specialized intermediate and final-good producers do not differ by too much. Interestingly, imperfect contracts may hinder or promote the prospects for equilibrium outsourcing.

${ }^{11}$ We use tildes to distinguish variables in an equilibrium with vertical integration. 
Each integrated firm produces an equal volume of inputs that are specialized to its needs and of the requisite high quality.

It is easy to see that an equilibrium with pervasive integration always exists. First, the equations (7) - (9) always give a solution with positive values for $\tilde{p}, \tilde{n}$ and $\tilde{y} \cdot{ }^{12}$ By construction, no integrated firm has an incentive to deviate, nor does any additional integrated firm have an incentive to enter. It remains to check only that no firm would wish to enter as a specialized intermediate-goods producer or a specialized final producer. But given that $n_{I}=n_{F}=0$ in the proposed equilibrium, a single firm that tries to enter as a specialized producer would find no counterpart with whom to interact. Such an entrant would search in vain for a partner and ultimately forfeit its entry cost.

Although an equilibrium with pervasive integration exists for all parameter values, it might be considered fragile in some circumstances. Let us suppose for the moment that a positive measure of specialized producers do enter the market in the proportions given by the equilibrium of the last section. We take the entry of these firms as exogenous, although the measure of such entrants can be arbitrarily small. Now let's ask, Would it be profitable for an additional stand-alone firm to enter once a few have done so already? If the answer is yes, we might regard the equilibrium with pervasive integration to be "unstable". 13

Consider the entry decision facing a potential final-good producer when a small positive measure of specialized firms is present in the industry and $k_{F}>k_{I} /(1-\alpha)$. In this situation, the input producers outnumber the final producers in the small group of specialized firms. Since the atomistic potential entrant is small relative to any finite measure of firms, it knows that if it enters, it will find a partner with probability very close to one. The firm can therefore expect to produce positive output and face demand of $A p^{-1 /(1-\alpha)}$, where $A=(L / \tilde{n}) \tilde{p}^{\alpha /(1-\alpha)}$. It can also expect

\footnotetext{
${ }^{12}$ However, for very high values of $k$, the solution yields a small measure of firms. This may strain the credulity of the assumption of a continuum of firms.

${ }^{13}$ The quotation marks here are meant to acknowledge that we have no explicit dynamics in the model. The entry by the first (small) group of firms would have to happen exogenously in order to spawn a process of entry by others.
} 
its eventual partner to supply it with a quantity of inputs such that its output will fetch a price of $2 / \alpha$. Finally, the entrant can expect to pay half of its revenue in its bargain with the supplier. In view of all this, the entrant can expect operating profits of $[k / 2(1-\alpha)](2 / \lambda)^{-\alpha /(1-\alpha)}$, which it compares with the fixed cost, $k_{F}$. Entry will be profitable in this case if and only if condition (6) of Proposition 1 is satisfied. The same conclusion applies when we do the calculation for the case in which $k_{I} /(1-\alpha)>k_{F}$. In other words, when an equilibrium with pervasive outsourcing exists, entry by a few specialized producers will render profitable the entry of many others. In this sense, the equilibrium with pervasive integration might be viewed as unstable under these circumstances.

\subsection{Mixed Equilibria}

So far, we have examined two types of industrial structures, one with vertically integrated firms and another with specialized firms whose relationships are governed by incomplete contracts. Now we explore the possibility that specialized and integrated firms might co-exist in the market.

To this end, suppose there exists an equilibrium with $n_{V}$ vertically integrated firms, $n_{I}$ entries by potential producers of intermediate inputs, and $n_{F}$ entries by potential producers of final products. In the equilibrium, the vertically integrated firms face a demand curve $A p^{-1 /(1-\alpha)}$ for some applicable value of the parameter $A$. It follows that their demand has constant elasticity, and so they price at a mark-up over their variable cost. Letting $p_{v}$ be the price charged by these firms, we have

$$
p_{v}=\frac{\lambda}{\alpha}
$$

The relationship between a specialized input producer and a specialized final producer plays out as before. The firms share the ex post surplus, which induces the component supplier to choose $x$ so that $\frac{1}{2} p x-x$ is maximized. The price here is the one implied by the inverse demand; i.e., $p=(x / A)^{-(1-\alpha)}$. The result is a quantity such that

$$
p_{s}=\frac{2}{\alpha}
$$


where $p_{s}$ is the price of a finished good sold by a specialized producer.

In the equilibrium, all vertically integrated firms must break even, while all firms that enter as specialized producers earn zero profits on average. Zero profits for vertically integrated producers requires $y_{v}\left(p_{v}-\lambda\right)=k$, or

$$
y_{v}=\frac{\alpha k}{(1-\alpha) \lambda} .
$$

If $n_{I} \geq n_{F}$, final producers match for sure, and earn zero profits if $\frac{1}{2} p_{s} y_{s}=k_{F}$. Then $y_{s}=\alpha k_{F}$. On the other hand, if $n_{F} \geq n_{I}$, all of the input producers find matches, in which case $y_{s}\left(p_{s} / 2-1\right)=k_{I}$. Combing these two, and using the expression for $p_{s}$, gives

$$
y_{s}=\alpha \kappa
$$

So, zero profits for all producers implies $y_{s} / y_{v}=(1-\alpha) \lambda \kappa / k$. On the other hand, utility maximization by consumers requires $y_{s} / y_{v}=\left(p_{v} / p_{s}\right)^{1 /(1-\alpha)}=(\lambda / 2)^{1 /(1-\alpha)}$. Evidently, an equilibrium with both integrated and specialized producers can only arise if $(1-\alpha) \lambda \kappa / k$ happens to equal $(\lambda / 2)^{1 /(1-\alpha)}$. In other words, condition (6) must hold as an equality. Clearly, this is a knife-edge case. ${ }^{14}$

\section{$5 \quad$ Welfare Properties}

Now that we have sorted out all of the possibilities for the industrial organization of the economy, we are in a position to evaluate the efficiency properties of the equilibria. Suppose first that there exists an equilibrium with pervasive outsourcing. Might welfare be higher in the equilibrium with vertical integration?

It is straightforward to compare levels of consumer welfare in the two equilibria. With pervasive outsourcing, $u=n y^{\alpha}=(L / 2) \alpha^{\alpha} \kappa^{\alpha-1}$ by (4) and (5). With vertical

\footnotetext{
${ }^{14}$ Our formulation does not allow for heterogeneity. Note, however, that an industry with heterogeneous firms can support vertical integration together with stand-alone firms. If, for example, the marginal cost parameter $\lambda$ differed across vertically integrated firms, with its values being drawn from identical but independent (across firms) distributions, then high cost firms would choose to leave the industry while low cost firms would choose to remain. Such firms can coexist with standalone producers.
} 
integration, $\tilde{u}=\tilde{n} \tilde{y}^{\alpha}=L(1-\alpha)^{1-\alpha} \alpha^{\alpha} k^{\alpha-1} \lambda^{-\alpha}$, by (8) and (9). It follows that $u \geq \tilde{u}$

if and only if $k / \kappa \geq(1-\alpha) \lambda(2 / \lambda)^{1 /(1-\alpha)}$, which is exactly the condition for the existence of an equilibrium with pervasive outsourcing. This proves

Proposition 2 When an equilibrium with pervasive outsourcing exists, it yields greater welfare to consumers than an equilibrium with vertical integration.

The equilibrium with pervasive outsourcing is not fully efficient, of course. Given the constraint that it takes one unit of labor to produce a unit of the intermediate, and $k_{F}+k_{I}$ units of labor to operate the firms that collaborate on each variety, it would be optimal to have $n^{*}=(1-\alpha) L /\left(k_{F}+k_{I}\right)$ varieties, with output $y^{*}=$ $\alpha\left(k_{F}+k_{I}\right) /(1-\alpha)$ of each one. The inefficiency reflects the distortion in the bilateral relationship between the producer pairs. However, no simple per unit or ad valorem tax or subsidy on sales of intermediate or final goods can be used by a benevolent government to improve on the equilibrium allocation.

Now suppose that an equilibrium with pervasive outsourcing does not exist. Would a benevolent government ever wish to tax entry by vertically integrated firms, perhaps to the point where an equilibrium with outsourcing would emerge? Again, the answer is no. First note that the equilibrium is efficient, given the constraint that all firms must be vertically integrated. ${ }^{15}$ Therefore, no small tax on integrated firms can generate a welfare gain. If the tax is large enough to induce a change in industrial organization, the equilibrium outcome would switch from $(\tilde{n}, \tilde{y})$ to $(n, y)$. But such a switch lowers welfare when condition (6) is violated.

\section{Partial Specialization}

The consequences of disagreement need not be so severe for an input supplier and final producer as what we have described so far. A supplier may be able to offer its

\footnotetext{
${ }^{15}$ This reflects the constrained optimality of the monopolistically competitive equilibrium, as demonstrated by Dixit and Stiglitz (1977). With $k$ units of labor required for each product variety, and $\lambda$ units of labor for each unit of output, $u$ is maximized by $n=\tilde{n}$ and $y=\tilde{y}$.
} 
services to another producer should its relationship with an initial partner dissolve. Similarly, a final producer may be able to find alternative sources for the inputs it needs. In this section, we extend the model to allow for these outside options.

When suppliers have market alternatives, they face an important trade-off that is absent from the simple model. On the one hand, an input that is highly specialized will be of maximal value to the prospective customer for whom it is designed. On the other hand, a more standardized and flexible input may be more valuable in alternative uses. The component supplier may be able to choose the degree of specificity of its product, trading off value within the intended relationship and value outside. Riordan and Williamson (1985) allowed the degree of specialization to be a choice variable for the buyer and seller in their analysis of the bilateral hold-up problem. We do likewise here, to see how the characterization of an industry equilibrium changes in this richer environment.

To capture input specificity, we associate each final good with an ideal component. The production of a unit of any final good requires one unit of some intermediate good. If the intermediate is the perfect one for that variety, then no further inputs are required. However, if the intermediate is not fully specialized to the needs of the producer, additional costs arise. The final producer must add labor when using a less-than-ideal component, the more so, the more different is the input from the producer's preferred specification.

In particular, we adopt a two-dimensional representation of the space of input characteristics. The ideal components for the various final products are arrayed along the circumference of a unit circle; see Figure 3. The point labelled $i$ represents the characteristics of an intermediate input that has been fully specialized to the needs of the producer of final good $i$. If this producer uses an input with characteristics different from these, it must employ extra resources to make the component "fit." We take the labor requirements per unit of intermediate to be an increasing and convex function of the distance between the intermediate actually used and the product's ideal component. Consider for example the input with characteristics represented by the point $s_{i}$ in the figure. This input has been designed with the needs of producer $i$ 


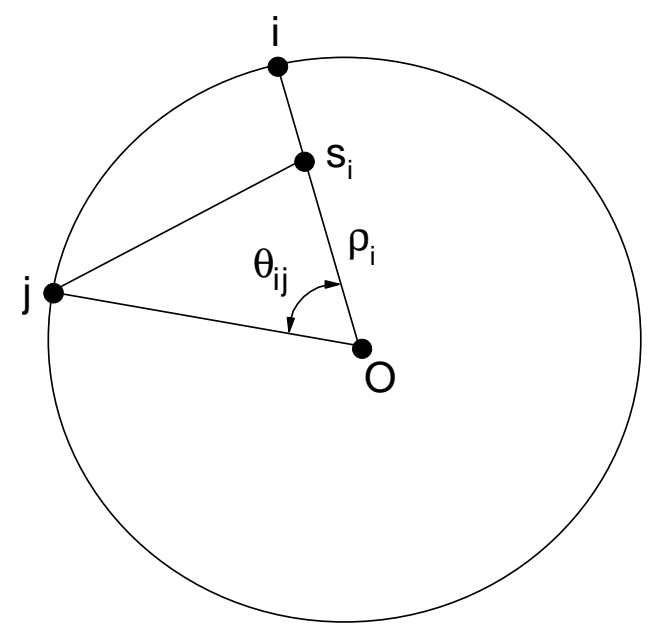

Figure 3: Input characteristics

in mind. However, it does not fully meet that producer's specifications. If the firm were to employ this input in producing good $i$, it would also need to hire labor per unit of the intermediate that reflects the distance $\overline{i s_{i}}$. If the producer of product $j$ instead were to use the component with characteristics described by point $s_{i}$, its labor costs per unit output would reflect the distance $\overline{j s_{i}}$ between the intermediate and this other producer's ideal. Evidently, an input can be used for purposes other than those for which it was initially intended, but doing so entails an additional cost.

For simplicity, we take the labor cost to be proportional to the square of the distance between an input and a producer's ideal, although other functions would do as well. We measure the degree of specialization of an input toward product $i$ by $\rho_{i}$, the distance of the input from the center of the circle along the radius leading to point $i$. The angle $\theta_{i j}$ measures (in radians) the similarity of the ideal components for goods $i$ and $j .{ }^{16}$ With these measures, we can write the labor cost to producer $i$ of using the input $s_{i}$ as $\beta\left(1-\rho_{i}\right)^{2}$ and the cost to producer $j$ of using the input $s_{i}$ as $\beta\left(1+\rho_{i}^{2}-2 \rho_{i} \cos \theta_{i j}\right)$. The input at the center of the circle is a "standardized" or "generic" input; it is not particularly well suited for any of the final producers, but is equally productive in all uses.

\footnotetext{
${ }^{16}$ We take the smaller angle between $i$ and $j$, so that $\theta_{i j} \leq \pi$.
} 
The rest of the model is basically as before. Firms incur fixed costs to enter as vertically integrated or specialized producers. Upon entry, specialized firms search for potential partners. Matching occurs randomly. When a supplier and a final producer meet, the latter provides the specifications for its ideal component, as well as technological information needed to produce any intermediate good. A potential input producer that fails to find a partner does not receive this information and has no choice but to exit the industry. ${ }^{17}$ Those component producers with working relationships choose the quantity, quality, and specification of their products.

After the components are produced, the prospective partners meet to negotiate a sale. It is at this stage that the outside options can make a difference. If the supplier rejects the buyer's offers, it has the possibility of selling its wares to another producer. Similarly, if the buyer refuses the supplier's demands, it might turn elsewhere for its components. However, a flexible technology is not enough to make for a secondary market. There must also be some sellers who are looking for buyers, and vice versa, at this later stage. Otherwise, a failed negotiation will leave each party searching in vain for a new partner.

To ensure the existence of a secondary market, we assume that a fraction $\delta$ of relationships dissolve exogenously. When a break down occurs, the input producer has no choice but to seek out a new customer for its (already produced) components. The final producer as well must locate a new supplier. The remaining negotiations take place against the backdrop of these exogenous separations. That is, when a component producer and final producer engage in bargaining, the threat for each is to leave the partnership and enter the secondary market where those who have been separated are searching for matches. We take $\delta$ to be very small. ${ }^{18}$ Still, the fact that it is not zero makes a difference, for it gives each of the firms in every partnership an outside option that otherwise would be lacking.

\footnotetext{
${ }^{17}$ Alternatively, we could assume that unmatched input producers can manufacture certain types of components (e.g., standardized inputs) without guidance from final producers. Then entrants who fail to find a partner in the first round might produce some components in the hope of finding a customer later. This case is a bit more complicated, but not essentially different.

${ }^{18}$ Technically speaking, we derive the limit equilibrium as $\delta$ approaches zero.
} 
Matching in the second stage is random, just as in the first. Firms with components to sell have an equal chance of meeting any of the final producers that are seeking inputs, and similarly, each final producer might be matched with any of the input firms. At this stage, there are an equal number of agents on each side of the market, and we assume each firm finds a new partner with probability one. In principle, there might be further separations and further rounds of matching after the second, but for simplicity we take the outside options after the second stage to be nil.

\subsection{Partial Specialization and Equilibrium Outsourcing}

We describe now an equilibrium with pervasive outsourcing. In this equilibrium, incomplete contracts govern all production. As before, we first characterize the equilibrium, including now the endogenous degree of input specialization. Then we examine the conditions for existence of an equilibrium of this sort.

It is convenient to begin with the secondary market. Consider a second-stage match between the specialized producer of variety $j$ and a firm with a quantity $x_{i}$ of a (high quality) input specialized to degree $\rho_{i}$ to the needs of the producer of good $i$. If a sale takes place, the final producer can produce output to meet the demand $A p(j)^{-1 /(1-\alpha)}$. The per unit cost of that output is $\phi\left(\rho_{i}, \theta_{i j}\right)$ for $y_{j} \leq x_{i}$, where $\phi\left(\rho_{i}, \theta_{i j}\right) \equiv \beta\left(1+\rho_{i}^{2}-2 \rho_{i} \cos \theta_{i j}\right)$ reflects the cost of tailoring the inputs to the needs of this particular producer. The quantity $x_{i}$ serves as a bound on the possible output of final good $j$.

Let $\Pi\left(\rho_{i}, x_{i}, \theta_{i j}\right)$ represent the maximal profits. Figure 4 depicts the determination of П. As usual, profit maximization entails a comparison of marginal revenue and marginal cost. The marginal revenue curve slopes downward; its location depends on the equilibrium value of the demand parameter $A$. Marginal cost is constant at $\phi\left(\rho_{i}, \theta_{i j}\right)$ for $y_{j} \leq x_{i}$, and becomes infinite at $x_{i}$. The figure depicts the case where it is optimal for the final producer to exhaust the stock of available inputs. Alternatively, it may be optimal to discard some of the components if they are not particularly well suited for the production of good $j$ (in which case, marginal cost is high). In any event, $\Pi\left(\rho_{i}, x_{i}, \theta_{i j}\right)$ represents the surplus that the partners can share if they meet in 


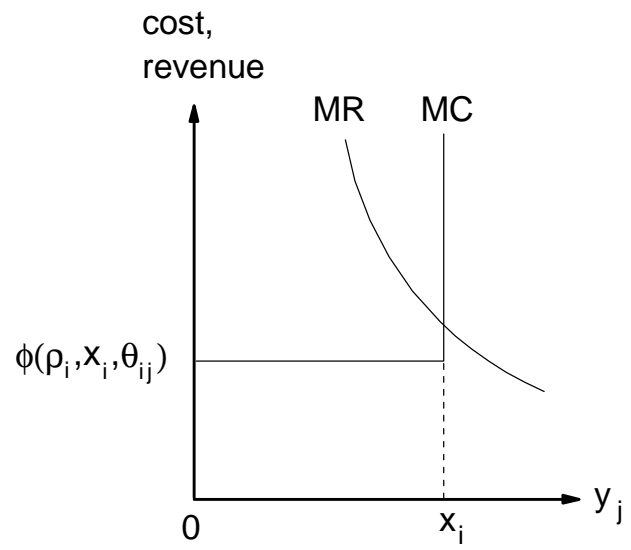

Figure 4: Choice of output in second-round match

the secondary market. With bargaining, they can expect to share this surplus evenly.

Now we can calculate the "outside options" available to firms of each type in the first round. If a final producer fails to strike a deal with its first round partner, it will enter the secondary market. There it can expect to find a match with probability one (because the secondary market has equal numbers on each side of the market). However, the firm faces uncertainty about the identity of a potential second-round supplier. The firm may find a supplier with components to sell that approximately fit its needs, or it may find one with components that are rather unsuitable. The outside option for the final producer, denoted $O_{F}(\rho, x)$, is the expected value of its share of second-round profits, or

$$
O_{F}(\rho, x)=\frac{1}{2 \pi} \int_{0}^{\pi} \Pi(\rho, x, \theta) d \theta
$$

The expectation is taken over the possible values of $\theta$, measuring the fit between a potential second round match and the final producer in question. We have omitted the subscripts $i$, because we seek a symmetric equilibrium in which all components are specialized to the same extent and the same quantity is produced of each one.

Similarly, an input producer who fails to come to terms with an initial partner can expect to find a second-round match with probability one. But here too there is uncertainty about the quality of that match. If the firm meets a final producer with 
needs close to what it has to offer, the second-round surplus will be large. Otherwise, it may be small. The expected proceeds for the input producer are half of the expected profits, or

$$
O_{I}\left(\rho_{i}, x_{i}\right)=\frac{1}{2 \pi} \int_{0}^{\pi} \Pi\left(\rho_{i}, x_{i}, \theta\right) d \theta .
$$

We leave the subscripts $i$ in (13) to remind ourselves that the outside option depends on the prior choices made by this particular input producer.

Now consider the first-round negotiation between an input supplier and its prospective partner. Let the partner be the producer of final good $i$. The final producer stands to reap revenues of $A^{1-\alpha} x_{i}^{\alpha}$ if the input supplier produces a quantity $x_{i}$ of high-quality inputs and if all these inputs are used to produce final output. ${ }^{19}$ The variable cost of the final output will be $\beta\left(1-\rho_{i}\right)^{2} x_{i}$ if the input is specialized to degree $\rho_{i}$. If the first-round match does not dissolve exogenously, the partners will share the surplus from the relationship, which is the difference between variable profits and the sum of the outside options of the two firms. Exogenous separations occur with probability $\delta$. Since we take $\delta$ close to zero, the input producer can expect (gross) earnings of

$$
O_{I}\left(\rho_{i}, x_{i}\right)+\frac{1}{2}\left[A^{1-\alpha} x_{i}^{\alpha}-\beta\left(1-\rho_{i}\right)^{2} x_{i}-O_{F}(\rho, x)-O_{I}\left(\rho_{i}, x_{i}\right)\right]
$$

if it produces $x_{i}$ units of the component and specializes it to degree $\rho_{i}$. This is the sum of the firm's outside option plus one-half of the surplus in its relationship with the producer of final good $i .^{20}$

The input producer chooses $\rho_{i}$ and $x_{i}$ to maximize expected profits net of manufacturing costs. Therefore, it solves

$$
\max _{\rho_{i}, x_{i}} \frac{1}{2}\left[A^{1-\alpha} x_{i}^{\alpha}-\beta\left(1-\rho_{i}\right)^{2} x_{i}+O_{I}\left(\rho_{i}, x_{i}\right)-O_{F}(\rho, x)\right]-x_{i} .
$$

The choice of specificity reflects a trade-off between the value of the components inside the relationship and their value in the secondary market. A higher value on the outside (higher $O_{I}$ ) means more bargaining power for the supplier when it negotiates

\footnotetext{
${ }^{19}$ The input producer would never manufacture more inputs than its first-round customer would use, because doing so adds cost without introducing the possibility of extra revenues at a later stage.

${ }^{20}$ In this equation, $\rho$ and $x$ represent the identical choices made by all other input producers in the symmetric equilibrium.
} 
with the final producer. The choice of quantity reflects, as before, a balancing of the marginal addition to the supplier's (half) share of operating profits and the (full) manufacturing cost.

We proceed now to characterize these choices. In order to avoid a taxonomy, we limit our attention to cases in which the cost of retrofitting components is not too large. In particular we adopt

Parameter Restriction 1: $\beta \leq 3 / 5$.

Recall from Figure 4 that a final-good producer may or may not use all of the components available from a second-round supplier, depending on the scale of market demand and the height of marginal cost. The parameter restriction will ensure that all components are in fact used, no matter how poor the second-round match happens to be.

Suppose it is optimal to use all components in any second-round match. Then, $\Pi\left(\rho_{i}, x_{i}, \theta_{i j}\right)=A^{1-\alpha} x_{i}^{\alpha}-\beta x_{i}\left(1+\rho_{i}^{2}-2 \rho_{i} \cos \theta_{i j}\right)$, the difference between revenues from the sale of $y_{j}=x_{i}$ units of the final good $j$ and the cost to the final producer of using the less-than-ideal components. The outside option $O_{I}\left(\rho_{i}, x_{i}\right)$ is one-half the expected profit across all possible second-round matches. Therefore,

$$
\begin{aligned}
O_{I}\left(\rho_{i}, x_{i}\right) & =\frac{1}{2 \pi} \int_{0}^{\pi}\left[A^{1-\alpha} x_{i}^{\alpha}-\beta x_{i}\left(1+\rho_{i}^{2}-2 \rho_{i} \cos \theta\right)\right] d \theta \\
& =\frac{1}{2}\left[A^{1-\alpha} x_{i}^{\alpha}-\beta x_{i}\left(1+\rho_{i}^{2}\right)\right] .
\end{aligned}
$$

The solution to (14) requires $\rho_{i}=2 / 3$ and $x_{i}=A \alpha^{1 /(1-\alpha)}\left(\frac{4}{3}+\frac{5}{9} \beta\right)^{-1 /(1-\alpha)}$.

In a symmetric equilibrium, $\rho_{i}=\rho$ for all $i$, so that

$$
\rho=\frac{2}{3} \text {. }
$$

Also, $y_{i}=x_{i}=x$ and $p_{i}=p$ for all $i$, so the expression for $x_{i}$ and (1) together imply ${ }^{21}$

$$
p=\left(\frac{4}{3}+\frac{5}{9} \beta\right) \frac{1}{\alpha} .
$$

\footnotetext{
${ }^{21}$ We can now check the conditions under which all available inputs will be used in a second-round match. With the demand function in (1), marginal revenue equals $\alpha p=4 / 3+5 \beta / 9$. The worst possible second-round match has $\theta=\pi$, and therefore $\phi=\beta(1+\rho)^{2}$. Since $\rho=2 / 3$, the maximum marginal cost is $25 \beta / 9$. But $\beta \leq 3 / 5$ ensures $4 / 3+5 \beta / 9 \geq 25 \beta / 9$.
} 
Evidently, input producers specialize their components only partially. This represents another disadvantage of arms-length dealing relative to vertical integration. The equilibrium value of $2 / 3$ reflects the particular (quadratic) form of the cost function and the assumption that parties bear equal weights in the bargain. However, an interesting and more robust observation is that $\rho$ does not depend on $\beta$. It might seem that input producers would be inclined to greater specialization when the costs of adaptation are large. However, the cost parameter affects not only the value of a component to its intended user, but also its value to others. When $\beta$ is large, the final producer's profits are sensitive to $\rho$, but so too is the outside option. These two effects offset one another, leaving the supplier's choice of specificity independent of $\beta$.

Comparing (16) with (3), we see that the equilibrium price of final goods is lower when a secondary market exists. ${ }^{22}$ This is because the outside option mitigates the hold-up problem. More components are produced, because the input producer has the opportunity to sell them to others if the initial partner fails to offer a reasonable price.

To complete the description of the equilibrium, we need to consider separately the cases in which input producers and final producers enter in larger numbers. If $n_{I} \geq n_{F}$, all final producers find first-round matches, and all such firms break even. Each initial match dissolves with probability $\delta$ close to zero. With probability close to one, a typical final producer receives revenues of $E / n$ and bears a cost of $\beta / 9$ for adapting each of $E / n p$ partially specialized components. The firm retains as operating profits its outside option $O_{F}(\rho, x)$ plus one-half of the surplus in its relationship with the input supplier. But this surplus is just equal to one-half of total revenues net of the adaptation costs. ${ }^{23}$ Recall that spending equals aggregate income, or $E=L$. Then, if operating profits for the final producer are to match total fixed costs, we

\footnotetext{
${ }^{22}$ Under Parameter Restriction 1, (16) implies $4 / 3 \alpha \leq p \leq 5 / 3 \alpha$, whereas the price of final goods is $2 / \alpha$ when there is no secondary market.

${ }^{23}$ The surplus to be shared is
}

$$
A^{1-\alpha} x^{\alpha}-\beta(1-\rho)^{2} x-O_{F}(\rho, x)-O_{I}(\rho, x) .
$$


must have $(L / 2 n)(1-\beta / 9 p)=k_{F}$, or

$$
n=\frac{L}{2 k_{F}}\left[\frac{12+(5-\alpha) \beta}{12+5 \beta}\right] .
$$

Output per firm equals $E / n p$, so

$$
y=\frac{18 \alpha k_{F}}{12+(5-\alpha) \beta} .
$$

If $n_{F} \geq n_{I}$, it is the input producers that find initial partners with probability one. An input producer pays $k_{I}$ in fixed costs and $x=E / n p=L / n p$ in manufacturing costs. Its proceeds are the sum of its outside option and one-half of the surplus in its relationship with a final producer, which again is one-half of total revenues of $L / n$ less one-half of the adaptation costs of $\beta L / 9 n p$. Zero profits requires equality between receipts of $(L / 2 n)(1-\beta / 9 p)$ and total costs of $k_{I}+L / n p$, or

$$
n=\frac{L}{2 k_{I}}\left[\frac{12+(5-\alpha) \beta-18 \alpha}{12+5 \beta}\right] .
$$

Of course, the number of firms must be positive, so an equilibrium of this type requires $\alpha<(12+5 \beta) /(18+\beta)$. In the event, output per firm is

$$
y=\frac{18 \alpha k_{I}}{12+(5-\alpha) \beta-18 \alpha} .
$$

Finally, we must identify when each case applies. We have $n=n_{F} \leq n_{I}$ if and only if

$$
\frac{k_{F}}{k_{I}} \geq \frac{12+(5-\alpha) \beta}{12+(5-\alpha) \beta-18 \alpha}
$$

and $\alpha<(12+5 \beta) /(18+\beta)$. Then (17) and (18) give the candidate values for $n$ and $y$. If the inequality runs the opposite direction and $\alpha<(12+5 \beta) /(18+\beta)$, equations (19) and (20) are the candidate values for $n$ and $y$. Finally, if $\alpha \geq(12+5 \beta) /(18+\beta)$, we cannot have $n_{F} \leq n_{I}$ or $n_{F} \geq n_{I}>0$. It follows that there can be no equilibrium But $O_{F}(\rho, x)=O_{I}(\rho, x)$, so the outside option plus one-half of the surplus equals

$$
O_{F}(\rho, x)+\frac{1}{2}\left[A^{1-\alpha} x^{\alpha}-\beta(1-\rho)^{2} x-2 O_{F}(\rho, x)\right]=\frac{1}{2}\left[A^{1-\alpha} x^{\alpha}-\beta(1-\rho)^{2} x\right] .
$$


with pervasive outsourcing when partial specialization is possible and the final goods are close substitutes.

As before, we can write the equilibrium conditions more succinctly. Suppose $\alpha<(12+5 \beta) /(18+\beta)$ and define

$$
\hat{\kappa} \equiv \max \left\{\frac{k_{F}}{\frac{2}{3}+\frac{(5-\alpha) \beta}{18}}, \frac{k_{I}}{\frac{2}{3}+\frac{(5-\alpha) \beta-18 \alpha}{18}}\right\} .
$$

Then, if an equilibrium with pervasive outsourcing and partial specialization exists, $\rho$ and $p$ are given by (15) and (16), while

$$
n=\frac{9}{12+5 \beta} \frac{L}{\hat{\kappa}}
$$

and

$$
y=\alpha \hat{\kappa} .
$$

For an equilibrium with pervasive outsourcing to exist, it must not be profitable for a vertically integrated firm to enter. A vertically integrated entrant would produce its ideal component at a cost of $\lambda$ per unit of output and would maximize profits by setting its price equal to $\lambda / \alpha$. At this price, its sales would be $A(\lambda / \alpha)^{-1 /(1-\alpha)}$, with $A=(L / n) p^{\alpha /(1-\alpha)}$ and $p$ given by (16). Using (21) we calculate the potential operating profits to be $(1-\alpha) \lambda \hat{\kappa}\left[\left(\frac{4}{3}+\frac{5}{9} \beta\right) / \lambda\right]^{1 /(1-\alpha)}$. Existence of an equilibrium with outsourcing requires that these profits be no greater than $k$.

We summarize the necessary and sufficient conditions for the existence of an equilibrium with pervasive outsourcing under Parameter Restriction 1 in the following proposition.

Proposition 3 When $\beta \leq 3 / 5$, there exists an equilibrium with partial specialization and pervasive outsourcing if and only if $\alpha<(12+5 \beta) /(18+\beta)$ and

$$
\frac{k}{\hat{\kappa}} \geq(1-\alpha) \lambda\left(\frac{\frac{4}{3}+\frac{5}{9} \beta}{\lambda}\right)^{\frac{1}{1-\alpha}} .
$$

As in the simple model, the existence of an equilibrium with outsourcing is more likely the larger is the excess fixed cost for integrated firms and the larger is the 


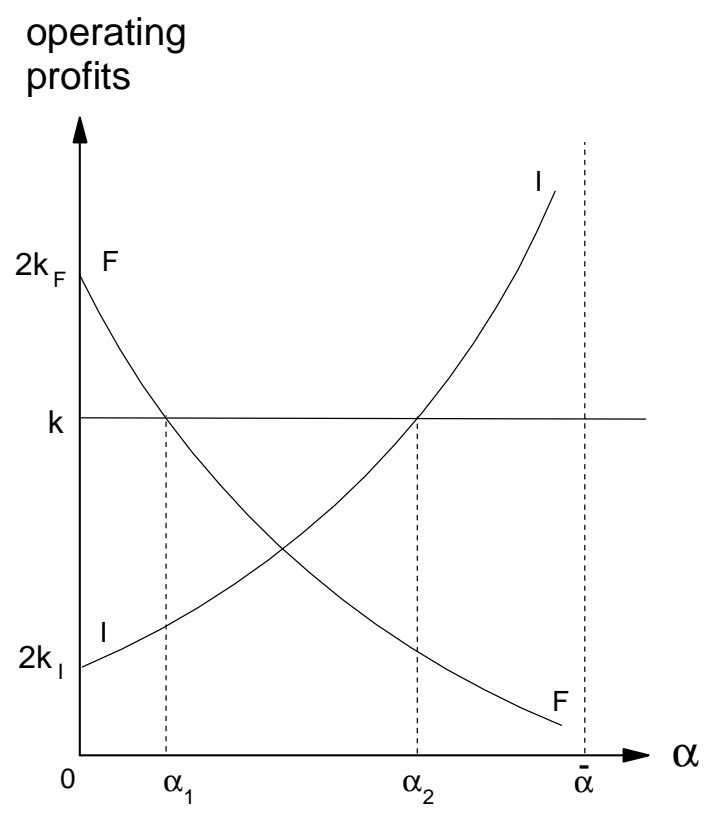

Figure 5: Existence of an equilibrium with pervasive outsourcing: variable $\rho$

productivity disadvantage of such firms. Now, an equilibrium with outsourcing never exists when the final goods are close substitutes. With $\alpha$ close to one, there is no possibility that input producers can break even in the face of the hold-up problem. Even if $\alpha$ is close to $(12+5 \beta) /(18+\beta)<1$, outsourcing cannot arise. As $\alpha$ approaches $(12+5 \beta) /(18+\beta)$, the input producers can break even only if there are very few of them. But with so few competitors, a vertically integrated firm can enter profitably, because it faces robust demand.

At the opposite extreme, when substitutability between products is poor, outsourcing can arise only if the excess governance costs for a vertically integrated firm are large. With $\alpha$ close to zero, (23) becomes $k \geq 2 \cdot \max \left\{k_{F}, k_{I}\right\}$. Notice that the condition no longer depends on $\lambda$ or $\beta$ and that it cannot be satisfied if $k \simeq k_{F}+k_{I}$.

Typically, an equilibrium with outsourcing will exist for an intermediate range of demand elasticities, as illustrated in Figure 5. Here, the curve $F F$ depicts the function $(1-\alpha) \lambda z\left[\left(\frac{4}{3}+\frac{5}{9} \beta\right) / \lambda\right]^{1 /(1-\alpha)}$ for $z=\frac{18 k_{F}}{12+(5-\alpha) \beta}$ while the curve $I I$ depicts the same function for $z=\frac{18 k_{I}}{12+(5-\alpha) \beta-18 \alpha}$. An equilibrium with outsourcing requires 
$\alpha \leq \bar{\alpha}=(12+5 \beta) /(18+\beta)$ and $k$ above both $F F$ and $I I$. In the figure, this happens when $\alpha$ lies between $\alpha_{1}$ and $\alpha_{2}{ }^{24}$

Figure 5 can also be used to study how the degree of input specificity affects the likely existence of an equilibrium with outsourcing. Recall that $\beta$ measures the extra cost per unit output of using a generic input relative to a fully specialized one. It is easy to verify that, for $\beta<3 / 5$, an increase in $\beta$ causes the $F F$ curve to shift upward and the $I I$ curve to shift downward. The intersections of these curves with the $k$ line both shift to the right. Therefore, an increase in $\beta$ raises $\alpha_{1}$, and thus the smallest value of the demand elasticity at which an equilibrium with outsourcing exists. But it also increases $\alpha_{2}$, and thus the largest demand elasticity for which such an equilibrium exists.

To understand this result, we must think about how changing $\beta$ affects the profitability of specialized firms. There is a direct effect of the increase in adaptation costs and an indirect effect that reflects the induced change in the output of intermediates. The direct effect reduces joint profits, given output, and both intermediate and final producers share in this loss. ${ }^{25}$ As for the indirect effect, we observe from (22) that $d x / d \beta=d y / d \beta<0$. An increase in adaptation costs reduces the incentive that input producers have to produce intermediates. Since the equilibrium output is smaller than the amount that maximizes revenues less adaptation costs, the indirect effect harms final producers as well. But the fall in output benefits intermediate producers. These producers choose their own $x_{i}$ to maximize profits, taking the output of their rivals as given. By the envelope theorem, a change in $x_{i}$ would have no first-order effect on a firm's profits, if others' output levels were to remain fixed. But the marginal output of each input producer generates a negative externality for

\footnotetext{
${ }^{24}$ While the figure shows the $I I$ curve as everywhere upward sloping, it can be U-shaped if $\lambda$ is large. This does not affect the conclusion that outsourcing typically requires an intermediate value for $\alpha$.

${ }^{25}$ Recall that each producer earns its outside option plus half of the surplus in the relationship. But, in equilibrium, the outside options are the same. So each side receives half of the revenues from the sale of the final goods less the adoptation costs. An increase in adaptation costs, holding output constant, reduces earnings for both partners.
} 
the others, by improving slightly the outside option for final-good producers. When all input producers reduce their outputs together, the marginal effect on their joint profits (for given $\beta$ ) is positive. Not only do input producers benefit from the indirect

effect of increasing $\beta$, but with $\beta<3 / 5$, the indirect effect must be stronger than the harmful direct effect.

Armed with the knowledge that increasing $\beta$ raises the profitability of intermediate producers and reduces that of final producers, we are ready to explain the finding illustrated in Figure 5. When $n_{I}>n_{F}$, it is the profitability of final producers that determines the total number of firms in the market. An increase in $\beta$ induces final producers to exit, and so expands the market for potential entry by a vertically integrated firm. In contrast, when $n_{F}>n_{I}$, it is the profitability of input producers that determines the totally number of varieties. Since an increase in $\beta$ raises profitability for these producers, it induces entry, which narrows the market for a vertically-integrated firm. In short, if $n_{I}>n_{F}$, an increase in $\beta$ narrows the range of values of $\alpha$ for which pervasive integration is sustainable, but if $n_{F}>n_{I}$, the opposite is true.

Our conclusions about the role of $\beta$ bear emphasizing. It might appear that high adaptation costs are inimical to outsourcing as a mode of industrial organization. After all, the more sensitive are manufacturing costs to the specifications of a component, the greater will be the inefficiency associated with partial specialization in any arms-length relationship. But, due to the equilibrium interaction between firms, outsourcing may occur in a market with moderately large adaptation costs, where the specialized input producers could not survive for smaller values of $\beta$.

\subsection{Vertical Integration versus Outsourcing}

The prospect of a secondary market in partially specialized components has no bearing on the existence of an equilibrium with only vertically-integrated firms. As in the simple model, such an equilibrium always exists; if no specialized firms enter the market, a producer contemplating such entry will foresee the futility in finding a partner. Indeed, the equilibrium in this case is exactly the same as in the simple 
model. The integrated entrants specialize their inputs fully to their own needs; i.e., $\rho_{i}=1$ for all $i$. Monopolistic competition ensues. The equilibrium values of $\tilde{p}, \tilde{n}$ and $\tilde{y}$ are given by (7) - (9), as derived in Section 4.1.

Moreover, there again exists no equilibrium with multiple modes of organization, except for special parameter values. Either all firms are vertically integrated, in which case entry by a single specialized producer is unprofitable, or all firms specialize in components or assembly, in which case a vertically-integrated entrant would lose money. The argument against mixed equilibria is exactly the same as in Section 3.2.

Finally, we can compare consumer welfare in an equilibrium with partial specialization and pervasive outsourcing with welfare in an equilibrium with pervasive integration and ideal components. Recall that welfare in a symmetric equilibrium is given by $u=n y^{\alpha}$ or $\tilde{u}=\tilde{n} \tilde{y}^{\alpha}$. In an equilibrium with pervasive outsourcing, $n=9 L /(12+5 \beta) \hat{\kappa}$ and $y=\alpha \hat{\kappa}$. In the equilibrium with vertical integration, $\tilde{n}=(1-\alpha) L / k$, while $\tilde{y}=\alpha k / \lambda(1-\alpha)$. Thus, the equilibrium with outsourcing delivers higher utility if and only if

$$
\frac{1}{\frac{4}{3}+\frac{5}{9} \beta} \hat{\kappa}^{-(1-\alpha)}>\lambda^{\alpha}(1-\alpha)^{1-\alpha} k^{-(1-\alpha)} \text {. }
$$

But it is apparent that this condition is the same as (23), which is one of the necessary conditions for the existence of an equilibrium with pervasive outsourcing. It follows that, whenever an equilibrium with pervasive outsourcing exists, such an equilibrium is socially preferred to one with vertically integrated producers.

\section{Conclusions}

We have incorporated familiar ideas from organization theory into a setting of general equilibrium. Like Williamson (1975, 1985), Grossman and Hart (1986), Hart and Moore (1990), and others, we have modeled a firm's "make or buy" decision as a trade-off between the transaction costs that stem from incomplete contracts and the excess governance costs associated with vertical integration. Our contribution has been to cast these decisions in an environment where a firm's market opportunities depend on the organizational choices of others. 
Our model allows us to pose questions that were outside the purview of the previous literature focusing on bilateral relationships. For example, we examined whether arms-length dealing between input suppliers and final producers is more likely to arise in competitive or monopolistic markets. We found that vertical integration is the most likely mode of organization in markets with intense competition or with little competition. Outsourcing typically requires an intermediate degree of market power. We also examined how the specificity of inputs affects the possibilities for arms-length dealing. The more sensitive are manufacturing costs to the detailed characteristics of the intermediates, the more costly will be the inefficiency arising from partial specialization of components under incomplete contracting. Still, an equilibrium with outsourcing may exist when the cost of using less-specialized components is reasonably large and fail to exist when this cost is small. This is because input specificity affects not only the size of the surplus in a relationship between a producer and its supplier, but also how that surplus is shared.

Finally, we studied the efficiency properties of the equilibrium choices of industrial organization. Here we found that consumer welfare is higher with specialized firms than with integrated firms whenever a free-entry equilibrium with outsourcing exists. On the other hand, if such an equilibrium does not exist, efficiency losses would attend any effort by a government to induce outsourcing by fiscal means. In this sense, the market choice of organizational mode is constrained efficient in our model.

The main contribution of this paper has been to provide a simple framework for studying the equilibrium mode of organization, the resulting degree of input specialization, and other variables of interest, such as prices, variety, and consumer welfare. Our model is simple enough to allow modifications and extensions, for example to a richer menu of contractual options and to alternative types of corporate partnerships. We are confident that it can be used to shed light on important issues, such as the increasing extent of internationalization that was mentioned in the introduction. In which types of countries will firms choose to operate as multinational corporations and in which will they deal at arms length, if factor prices and transport costs make foreign production optimal? When might joint ventures arise as an alternative to the 
two more extreme modes of industrial organization? What are the distributional and policy implications of international outsourcing? Do long term contracts between national firms operate as barriers to trade? These are the types of questions we hope to be able to address with our model. 


\section{Appendix}

In this appendix, we describe an equilibrium with pervasive outsourcing for an economy in which stand-alone producers of intermediate inputs and final goods can write binding contracts. By comparing this equilibrium with that described in Section 3 , we can better understand the implications of incomplete contracts for the viability of an equilibrium with pervasive outsourcing. Even without contracting problems, specialized firms suffer a disadvantage relative to vertically integrated firms, because they must find partners. ${ }^{26}$ The following analysis isolates the disadvantage of specialization arising from matching alone.

The model is the same as in Section 3, except that matched firms can now sign binding contracts. When two specialized firms meet, they bargain over the quantity and quality of the intermediate input and its price. The parties sign an enforceable contract that dictates these terms. The input producer manufactures the specified quantity of intermediate goods and exchanges them for the agreed payment. In the last stage, the final-good producer assembles the finished product and sells it to consumers.

Consider the bargaining stage. At this stage, each side has incurred the fixed cost of entry, but neither has borne any manufacturing costs. Since the outside options are zero, each firm expects to receive half of the surplus, which now equals $p y-y-m_{I}-m_{F}$. The surplus is simply revenue less the joint manufacturing costs (fixed and variable) of the partners. The firms agree on the volume of inputs that maximizes the surplus in light of the demand given by (1). The resulting contract specifies the quantity as $x=A \alpha^{\alpha /(1-\alpha)}$ and the quality as high. It also indicates a payment to the intermediate producer that gives the firm half of the surplus. With $y=x$, the chosen output implies a consumer price of

$$
p_{c}=\frac{1}{\alpha}
$$

which is one half the price without contracting (see [3]). ${ }^{27}$ Noting that, in equilibrium,

\footnotetext{
${ }^{26}$ We thank Oliver Hart for this observation.

${ }^{27}$ We use a subscript $c$ to denote equilibrium values in the economy with perfect contracts.
} 
$E=L=n_{c} p_{c} y_{c}$, half of the surplus amounts to

$$
\frac{1}{2}\left[(1-\alpha) \frac{L}{n_{c}}-m_{I}-m_{F}\right]
$$

Now we have two possible cases: either $n_{I} \geq n_{F}$ or $n_{I} \leq n_{F}$. If input producers are more numerous, the final-good producers find a match with probability one. Then, half of the surplus must cover their fixed cost of entry, $e_{F}$. This requires $n_{c}=n_{F}=(1-\alpha) L /\left(k_{I}+k_{F}+e_{F}-e_{I}\right)$. If, on the other hand, final-good producers are more numerous, it is the input producers who find matches with probability one. Then half of the surplus must cover their entry costs, which implies $n_{c}=$ $n_{I}=(1-\alpha) L /\left(k_{I}+k_{F}+e_{I}-e_{F}\right)$. We can combine these implications in a single equation, namely

$$
n_{c}=\frac{L}{\kappa_{c}}
$$

where

$$
\kappa_{c}=\frac{1}{1-\alpha}\left(k_{I}+k_{F}+\left|e_{F}-e_{I}\right|\right),
$$

and $\left|e_{F}-e_{I}\right|$ is the absolute difference between the two costs of entry.

In this equilibrium, $n_{c}=n_{F} \leq n_{I}$ whenever $e_{F} \geq e_{I}$ and $n_{c}=n_{I} \leq n_{F}$ whenever $e_{I} \geq e_{F}$. That is, the comparative sizes of the entry costs determine which is the long end of the market. Since $y_{c}=L / p_{c} n_{c}$, it follows from (A1) and (A2) that

$$
y_{c}=\alpha \kappa_{c}
$$

and $A_{c}=\kappa_{c} \alpha^{-\alpha /(1-\alpha)}$.

Now consider the possible entry of a vertically integrated firm. This firm would face the demand $A_{c} p^{-1 /(1-\alpha)}=\kappa_{c} \alpha^{-\alpha /(1-\alpha)} p^{-1 /(1-\alpha)}$. It would maximize profits by charging a price $\lambda / \alpha$ and thereby earn operating profits of $(1-\alpha) \kappa_{c} \lambda^{-\alpha /(1-\alpha)}$. An equilibrium with pervasive outsourcing can exist only if such entry is not profitable. Entry by the integrated firm will not profitable if and only if

$$
k \lambda^{\frac{\alpha}{1-\alpha}} \geq k_{I}+k_{F}+\left|e_{F}-e_{I}\right|
$$

Condition (A3) is a necessary and sufficient condition for the existence of an equilibrium with pervasive outsourcing. It is the counterpart to (6) in the model with 
imperfect contracts. Since $\lambda \geq 1$ and $k \geq k_{I}+k_{F}$, the condition is satisfied whenever the absolute difference in the entry costs $\left|e_{F}-e_{I}\right|$ is sufficiently small. With equal entry costs for both types of stand-alone firms, every entrant can find a match. Then there is no disadvantage to specialized entry, and the manufacturing cost advantages ensure that outsourcing is viable. If, on the other hand, the difference in entry costs is large, many entrants on one side of the market will fail to find a match. The potential for waste due to excessive entry can undermine the existence of an equilibrium with outsourcing.

To see how imperfect contracting affects the prospects for outsourcing, we write (6) in a form comparable to (A3). Using the definition of $\kappa$, and rearranging terms, we find that an equilibrium with pervasive outsourcing exists in an a world of imperfect contracting if and only if

$$
k \lambda^{\frac{\alpha}{1-\alpha}} \geq 2^{\frac{1}{1-\alpha}} \max \left\{k_{I},(1-\alpha) k_{F}\right\}
$$

Condition (A4) may be more or less restrictive than (A3). For example, if $e_{F}=e_{I}$, (A3) will be satisfied but (A4) may fail. Then an equilibrium with outsourcing can be sustained with perfect contracting, but not with imperfect contracts. On the other hand, if $\alpha \approx 0$ and $\left|e_{F}-e_{I}\right| \approx k_{F}>k_{I}$, then (A4) may be satisfied (for $k>2 k_{F}$ ) but (A3) may fail (if $k<2 k_{F}+k_{I}$ ).

Evidently, imperfect contracting may hinder the prospects for outsourcing, but also may make outsourcing sustainable where otherwise it would not be. On the one hand, imperfect contracts cause an inefficient supply (and, with partial specialization, also an inefficient type) of input, which impedes the ability of specialized producers to compete with an integrated firm. On the other hand, the perfect contracts induce a different sharing of the fixed manufacturing costs by the two types of specialized firms. Since the sharing of fixed costs helps determine the incentives for entry, the excessive entry on one side of the market may be exacerbated or alleviated by perfect contracting. 


\section{References}

[1] Abraham, Katharine G. and Taylor, Susan K. (1996), "Firm's Use of Outside Contractors: Theory and Evidence," Journal of Labor Economics, 14, 394-424.

[2] Aghion, Philippe, Dewatripont, Mathias and Rey, Patrick (1994), "Renegotiation Design with Unverifiable Information," Econometrica, 62, 257-282.

[3] Audet, Denis (1996), "Globalization in the Clothing Industry," in Globalization of Industry: Overview and Sector Reports, Paris: Organization for Economic Cooperation and Development.

[4] Campa, José and Goldberg, Linda (1997), "The Evolving External Orientation of Manufacturing Industries: Evidence from Four Countries," NBER Working Paper No. 5958, Cambridge MA.

[5] Coase, Ronald H. (1937), "The Nature of the Firm," Economica, 4, 386-405.

[6] Dixit, Avinash K. and Stiglitz, Joseph E. (1977), "Monopolistic Competition and Optimum Product Diversity," American Economic Review, 67, 297-308.

[7] Feenstra, Robert C. (1998), "Integration of Trade and Disintegration of Production in the Global Economy," Journal of Economic Perspectives, 12, 31-50.

[8] Grossman, Sanford J. and Hart, Oliver (1986), "The Costs and Benefits of Ownership: A Theory of Vertical and Lateral Integration," Journal of Political Economy, 94, 691-719.

[9] Hart, Oliver (1995), Firms, Contracts, and Financial Structure, Oxford: Oxford University Press.

[10] Hart, Oliver and Moore, John (1990), "Property Rights and the Nature of the Firm," Journal of Political Economy, 98, 1119-1158.

[11] Hart, Oliver and Moore, John (1999), "Foundations of Incomplete Contracts," Review of Economic Studies, 66, 115-138. 
[12] Helper, Susan (1991), "Strategy and Irreversibility in Supplier Relations: The Case of the U.S. Automobile Industry," Business History Review, 65, 781-824.

[13] Hummels, David, Rapoport, Dana and Yi, Kei-Mu (1998), "Vertical Specialization and the Changing Nature of World Trade," Federal Reserve Bank of New York Economic Policy Review, 4, 79-99.

[14] Klein, Benjamin, Crawford, Robert G. and Alchian, Armen A. (1978), "Vertical Integration, Appropriable Rents, and the Competitive Contracting Process," Journal of Law and Economics, 21, 297-326.

[15] Maskin, Eric and Tirole, Jean (1999), "Unforeseen Contingencies and Incomplete Contracts," Review of Economic Studies, 66, 83-114.

[16] Riordan, Michael H. and Williamson, Oliver E. (1985), Asset Specificity and Economic Organization," International Journal of Industrial Organization, 3, 365-378.

[17] McLaren, John (1998), “Globalization' and Vertical Structure," mimeo, Columbia University.

[18] Segal, Ilya (1999), "Complexity and Renegotiation: A Foundation for Incomplete Contracts," Review of Economic Studies, 66, 57-82.

[19] Williamson, Oliver E. (1975), Markets and Hierarchies: Analysis and Antitrust Implications, New York: Free Press.

[20] Williamson, Oliver E. (1985), The Economic Institutions of Capitalism, New York: Free Press.

[21] World Trade Organization (1998), Annual Report 1998, Geneva: World Trade Organization.

[22] Yeats, Alexander J. (1998), "Just How Big is Global Production Sharing?" Policy Research Working Paper No. 1871, The World Bank Development Research Group. 
</ref_section> 